\title{
KESIAPAN GURU RA DALAM MELAKUKAN PEMBELAJARAN DARING DI BANGKALAN
}

\author{
Eriqa Pratiwi ${ }^{1}$, Dinda Rizki Tiara ${ }^{2}$ \\ Fakultas Ilmu Pendidikan, Universitas Trunojoyo Madura ${ }^{12}$ \\ Email: eriqa.pratiwi@trunojoyo.ac.id ${ }^{1}$, dinda.rtiara@trunojoyo.ac.id ${ }^{2}$ \\ Pratiwi, Eriqa. Dinda Rizki Tiara,. (2021). Kesiapan Guru RA dalam Melakukan Pembelajaran Daring di \\ Bangkalan. Jurnal Pelita PAUD, 5(2), 222-228. \\ doi: https://doi.org/10.33222/pelitapaud.v4i1.780
}

Diterima: 06-05-2021

Disetujui: 27-05-2021

Dipublikasikan: 19-06-2020

\begin{abstract}
Abstrak: Pandemi Covid-19 menjadikan pembelajaran luring menjadi daring di semua jenjang pendidikan agar pembelajaran tetap bisa dilaksanakan dengan hasil yang baik. Kesiapan guru dalam pembelajaran merupakan kunci keberhasilan dari pembelajaran itu sendiri. Kesiapan guru dibutuhkan tak terkecuali pembelajaran daring pada pendidikan anak usia dini. Penelitian ini bertujuan untuk melihat bagaimana kesiapan guru RA di Bangkalan dalam melaksanakan pembelajaran daring. Penelitain ini dilaksanakan di RA di Bangkalan. Pendekatan yang digunakan dalam penelitian ini yaitu pendekatan deskriptif asosiatif (Korelasi Product Moment). Subjek dalam penelitian ini diambil berdasarkan rumus Slovin dari total populasi guru RA di Bangakalan sebanyak 395 sehingga didapatkan 199 guru RA, namun penelitian ini menggunakan 210 guru. Pengumpulan data dilakukan dengan mengadaptasi skala TROLM dan dianalisis dengan teknik Confirmatory Factor Analysis (CFA). Hasil yang didapatkan adalah kesiapan guru RA di Bangakalan cukup tinggi dalam melaksanakan pembelajaran daring.
\end{abstract}

Kata kunci: Kesiapan Guru, Pembelajaran Daring, Pendidikan Anak Usia Dini

Abstract: The Covid-19 pandemic has made offline learning online at all levels of education so that learning can still be carried out with good results. Teacher readiness in learning is the key to the success of the learning itself. Teacher readiness is needed, including online learning in early childhood education. This study aims to see how the readiness of $R A$ teachers in Bangkalan in implementing online learning. This research was conducted at RA in Bangkalan. The approach used in this research is associative descriptive approach (Product Moment Correlation). The subjects in this study were taken based on the Slovin formula from the total population of $R A$ teachers in Bangakalan as many as 395 so that 199 RA teachers were obtained, but this study used 210 teachers. The data was collected by adapting the TROLM scale and analyzed using the Confirmatory Factor Analysis (CFA) technique. The results obtained are that the readiness of RA teachers in Bangkalan is quite high in carrying out online learning.

Keywords: Teacher Readiness, Online Learnig, Early Childhood Education

http://jurnal.upmk.ac.id/index.php/pelitapaud 


\section{PENDAHULUAN}

Pandemi Covid-19 membuat semua sisi kehidupan manusia berubah dan beradaptasi dengan yang cara yang baru tak terkecuali dalam bidang pendidikan. Surat Edaran Nomor 4 Tahun 2020 tentang Pelaksanaan Kebijakan Pendidikan dalam Masa Darurat COVID-19 mewajibkan seluruh jenjang pendidikan harus melakukan kegiatan belajar dari rumah dan dilakukan secara daring, termasuk pembelajaran dalam pendidikan anak usia dini. Pembelajaran dalam pendidikan anak usia dini yang selama ini dilakukan secara luring agar anak dapat lebih aktif dan belajar secara langsung harus berubah dengan belajar secara daring (Cahyati \& Kusumah, 2020).

Himbauan pelaksanaan pembelajaran secara daring merupakan salah satu cara untuk dapat mempertahankan kesehatan masyarakat dan sekaligus untuk memastikan proses pembelajaran tetap berlangsung sehingga aspek perkembangan anak tetap dapat berkembang secara optimal, meskipun ternyata banyak orangtua yang memiliki pandangan negatif terhadap pembelajaran daring. (Dong, Cao, \& Li, 2020). Ternyata pandangan tersebut sejalan dengan kenyataannya hasil pembelajaran yang diharapkan cukup sulit tercapai. Pada pelaksanaan pembelajaran dari saat pademi Covid-19 pencapaian perkembangan di beberapa aspek perkembangan mengalami penurunan (Wulandari \& Purwanta, 2020). Penurunan pada aspek perkembangan anak usia dini merupakan salah satu bentuk penurunan hasil belajar yang terjadi pada pelaksanaan pembelajaran daring. Hal tersebut memang dapat dipicu dengan adanya tantangan dalam pembelajaran daring, (Cahyati, 2020) seperti koneksi internet, kurangnya perangkat pembelajaran yang dimiliki guru dan siswa maupun siswa, kurang terampilnya guru dalam penggunaan perangkat teknologi digital dan ketidakhadiran guru secar fisik yang berpengaruh pada makna pembalajaran (Ferri, dkk, 2020). Hal tersebut tentunya bisa menjadi alasan terjadinya penurunan aspek perkemabangan anak dalam pembelajaran daring jika tidak semua agen siap untuk melaksanakannya.

Pembelajaran dalam pendidikan anak usia dini membutuhkan persiapan yang matang, baik dari sekolah, pendidik hingga kondisi dari anak sebagai perserta didik ataupun dukungan orangtua. Teknologi, karakteristik pengajar dan karakteristik siswa merupakan faktor penentu dari keberhasilan pembelajaran daring (Andrianto Pangondian et al., 2019). Ketersediaan sarana dan prasarana, kurang pemahaman serta ketidaksiapan guru maupun orangtua menjadi sebuah promblematika yang tidak terhindari dari pelaksanaan pembelajaran daring (Harahap et al., 2021). Selain itu juga terdapat guru yang belum siap dalam melaksanakan pembelajaran daring karena beberapa faktor (Ayuni et al., 2020). Keadaan tersebut menunjukkan pentingnya kesiapan guru dalam pembelajaran daring yang saat ini mulai menjadi metode dalam pembelajaran di pendidikan anak usia dini.

Kesiapan guru dalam pembelajaran daring sangat dipengaruhi oleh beberapa hal, mulai dari diri guru itu sendiri hingga lingkungan sekitar guru, termasuk dukungan. Dukungan yang tak kalah pentingnya adalah dari kepala sekolah sebagai supervisor yang dapat meningkatkan profesionalisme seorang guru dalam mengajar dan hal ini sesuai hasil penelitian yang di lakukan oleh Lisna yang menunjukkan bahwa, peran kepala sekolah sebagai supervisor untuk meningkatkan profesionalisme guru yaitu: (1) mengunjungi kelas yang sedang berlangsung pembelajaran, (2) mengobservasi keadaan pembelajaran dikelas, (3) mewawancara para guru.

Kesiapan guru dalam pembelajaran menjadi salah satu bentuk profesionalitas dan pedagogi guru. Untuk melakukan pembelajaran daring yang efektif adalah dengan mengukur kesiapan guru sebagai salah satu pemangku kepentingan, sehingga dapat melakukan asesmen dalam penerapan pembelajaran daring (Ke et al., 2020). Kesiapan guru pada pembelajaran daring ini secara umum dapat dilihat dari keadaan emosi, pengetahuan dan juga sikap terhadap pelaksanaan pembelajaran daring. Terdapat beberapa skala yang telah mengembangkan alat untuk mengukur kesiapan guru dalam pembelajaran daring, dari kemampuan mengelola waktu kerja dan belajar secara daring ataupun salah satunya adalah kemampuan guru dalam menggunakan teknologi sebagai sumber belajar dan alat dalam pembelajaran (Ha et al., 2014). Dimensi tersebut cukup diragukan di Indonesia. Sayangnya guru di Indonesia secara umum masih dirasa kurang menguasai 
penggunaan teknologi di dalam pembelajaran (Churiyah et al., 2020). Terlebih lagi bagi lembaga yang memiliki tambahan pendidikan agama seperti lembaga Raudhatul Athfal (RA). Lembaga RA ini memiliki dasar pendidikan agama sebagai ciri khasnya dan sebagian lembaga RA di Bangkalan merupakan lembaga di bawah yayasan Pondok Pesantren, yang mana salah satu permasalahannya pada IT dikarenakan sarana prasarana yang masih sangat sederhana (Saputro, 2018). Berdasar-kan keadaan yang ada dirasa penting untuk mengetahui kesiapan guru RA di Bangkalan pada pembelajaran daring.

\section{METODE PENELITIAN Jenis Penelitian}

Metode penelitian yang di gunakan yaitu kuantitatif (deskriptif asosiatif) dengan pendekatan survey, hal ini karena adanya variabel-variabel yang akan ditelah hubungannya serta tujuan untuk menyajikan gambaran secara terstruktur, faktual dan akurat mengenai fakta-fakta serta hubungan variabel yang diteliti. Adapun pengertian metode deskriptif menurut Sugiyono (2012: 35).

\section{Waktu dan Tempat Penelitian}

Penelitian kesiapan guru dalam pembelajaran daring ini dilakukan pada saat pandemi covid 19 yang dimulai pada bulan maret 2020 hingga agustustus 2020 di Kabupaten Bangkalan yang mana pada waktu bersamaan mengalami penurunan pada statusnya pada Indeks Pembangunan Manusia.

\section{Subjek Penelitian}

Subjek dalam penelitian ini diambil berdasarkan rumus Slovin dari total populasi guru RA di Bangakalan sebanyak 395 sehingga didapatkan 199 guru RA, namun penelitian ini menggunakan 210 guru.

\section{Prosedur}

Prosedur sebagai rancangan pemerolehan data dalam Penelitian ini diperoleh dengan menggunakan alat dengan skala TROLM (Teaching Readinnes of Online Learning Measurement), yang telah melalui pemilihan skala, proses adaptasi dan dikembangkan dengan teknik Delphi. Berdasarkan teknik tersebut, maka dapat diketahui ke tingkat adaptasi skala TORLM untuk dilakukan pada guru RA di Bangkalan dan juga dapat secara valid mengukur tingkat kesiapan guru RA di Bangkalan pada pembelajaran daring.

Data, Intrumen, dan Teknik Pengumpulan Data

Data dikumpulkan dengan dua instrumen dalam metode survey, yaitu kuesioner (pertanyaan tertulis) dan wawancara (pertanyaan lisan). Pengumpulan data dalam penelitian ini dilakukan dengan kepustakaan dan lapangangan (field research) untuk melihat kesiapan guru RA di Kabupaten Bangkalan terhadap pembelajaran daring.

\section{Teknik Analisis Data}

Teknik analisis dalam penelitian ini yaitu dengan analisis Confirmatory Factor Analysis (CFA). Analisis ini digunakan untuk mengidentifikasi hubungan antara variabel indikator dalam membangun sebuah konstruk.

\section{HASIL PENELITIAN DAN PEMBAHASAN}

Pandemi Covid 19 memaksa pelaksanaan pembelajaran di pendidikan anak usia dini dilakukan secara daring. Guru harus bisa beradaptasi dengan keadaan yang ada dan mampu melakukan pembelajaran dengan baik, meskipun memiliki beberapa kendala. Terdapat beberapa kendala pelaksanaan pembelajaran daring, yaitu fasilitas PAUD yang kurang memadai, kurangnya pengetahuan tentang aplikasi dan penggunaanya, ketidaktersediaan kuota dan jaringan internet serta gawai (Jayawardana et al., 2020). Kesulitan tersebut akan mempengaruhi kesiapan dan kemampuan guru dalam melakukan pembelajaran daring.

Covid 19 membuat pembelajaran daring menjadi kurang efektif dilakukan, karena banyak guru atau sarana yang tidak menunjang selama pembelajaran daring (Sutarna et al., 2022)

Penelitian tentang kesiapan guru RA di Bangkalan pada pembelajaran daring ini akan memperlihatkan hasil kelayakan skala untuk diadaptasi sebagai alat ukur dan juga memperlihatkan hasil pengukuran kesiapan guru. Pada proses uji kelayakan dan adaptasi skala dilakukan beberapa tahap. Selanjutnya akan menjelaskan tentang hasil pengukuran kesiapan guru terhadap pembelajaran daring. 
Penelitian tentang kesiapan guru dalam pembelajaran daring perlu dilakuan untuk memastikan pembelajaran daring dapat dilakukan dengan baik dan menghasilkan outcome yang baik. Namun sayangnya alat ukur untuk melihat kesiapan guru dalam pembelajaran daring khususnya guru pendidikan anak usia dini di Indonesia masih belum dikembangkan. Hal ini menjadikan perlunya menggunakan skala lain yang sesuai dengan karakteristik demografi guru yang menjadi subjek penelitian.

Skala yang diambil dan digunakan dalam penelitian ini adalah skala Teacher Readiness for Online Learning Maeasure (TROLM) yang dikembangkan sebelumnya (Hung, 2016) yang melihat dari beberapa dimensi yaitu communication self-efficacy, institutional support, self-directed, dan learning transfer self-efficacy. Skala ini dipilih sebagai alat ukur pada penelitian ini karena skala telah diuji coba dan terbukti valid dalam penelitian kesiapan guru dalam pembelajaran daring di tingkat sekolah dasar dan sekolah menengah pertama. Dibandingkan skala lain, skala TROLM ini merupakan skala yang paling dekat tingkatnya dengan tingkat pendidikan anak usia dini.

Berdasarkan hasil translasi dan validasi yang dilakukan oleh para ahli dalam tahapan content validity, skala TROLM dapat dijadikan alat ukur dalam penelitian ini. Ketepatan pemilihan alat ukur diperkuat dengan hasil pelaksanaan uji construct validity, menggunakan metode the factor analysis. Kaiser Meyer Olkin (KMO) digunakan untuk melihat kelayakan sautu variabel agar dapat dilanjutkan pada analisis faktor. Hasil dari Kaiser Meyer Olkin (KMO) menunjukan bahwa hasilnya dengan nilai 0.932. Syarat kecukupan sampel dalam analisis faktor dengan nilai $0,932>0,5$ dengan Sig $0.000<0,05$, sehingga analisis faktor yang telah dicoba dapat terus dilakukan. Selain menggunakan Kaiser Meyer Olkin (KMO) untuk mengetahui kelayakan variabel, selanjutnya metode yang digunakan adalah menggunakan Anti Image Correlation. Anti Image Correlation digunakan untuk mengetahui dan menentukan variabel mana yang layak dipakai dan dianalisis faktor, yaitu dengan syarat nilai di atas 0.5 . Hasil dari nilai Anti-Image Correlation menunjukkan nilai Measure of sampling Adequacy (MSA) dimana semua butir bernilai di atas 0.5, sehingga analisis faktor dapat dilanjutkan.

Setelah mengetahui bahwa butir tersebut dapat digunakan untuk analisis faktor, maka selanjutnya akan melakukan uji validitas dengan menggunakan korelasi product moment. Korelasi product moment dianggap mampu digunakan untuk melihat hubungan variabel. Berdasarkan dari hasil uji validasi yang dilakukan varibel tersebut menunjukkan bahwa variabel tersebut valid dan bisa dilanjutkan dengan menguji reliabilitas. Uji reliabilitas dilakukan untuk melihat apakah skala tersebut dapat diterapkan pada populasi yang dituju. Uji reliabilitas pada penelitian ini menggunakan Cronbach's Alpha. Hasil dari perhitungan uji reliabilitas menghasilkan nilai 0.961 , yang mana variabel tersebut reliable dengan nilai lebih dari 0.60 , artinya instrument angket tersebut memiliki reliabilitas yang sangat kuat atau tinggi. Sehingga selanjutnya disusunlah angket untuk mengukur kesiapan guru RA di Bangkalan pada pembelajaran daring.

Tabel 1. Hasil Analisis Statistik Deskriptif

Frequencies

\section{Statistics}

Kesiapan Guru Pada Pembelajaran Daring di RA se Bangkalan

\begin{tabular}{|l|l|}
\hline N $\quad$ Malid & 210 \\
Mean & 0 \\
Std. Error of Mean & 70.5381 \\
Median & .86314 \\
Mode & 71.5000 \\
Std. Deviation & 72.00 \\
Variance & 12.50803 \\
Skewness & 156.451 \\
Std. Error of Skewness & -1.425 \\
Kurtosis & .168 \\
Std. Error of Kurtosis & 3.576 \\
Range & .334 \\
Minimum & 72.00 \\
Maximum & 18.00 \\
Sum & 90.00 \\
\hline
\end{tabular}

Berdasasarkan output SPSS di atas, dapat diketahui bahwa skor kesiapan guru PAUD dalam pembelajaran daring memiliki mean sebesar 70,54; median sebesar 71,50; modus sebesar 72,00; variansi sebesar 156,45; standar deviasi sebesar 12,51; nilai maksimum sebesar 90,00 dan nilai minimum sebesar 
18,00. Selanjutnya skor kesiapan guru PAUD dalam pembelajaran daring tersebut dikategorisasikan menjadi 5 (lima) kategori/tingkatan dengan menggunakan acuan skor standar mean ideal dan standar deviasi ideal, sehingga dihasilkan atergorisasi kesiapan guru sebagai berikut:

Tabel 2. Kategorisasi Kesiapan Guru

\begin{tabular}{|c|c|c|}
\hline No. & Interval & Kategori \\
\hline 1. & di atas $(\mathrm{Mi}+1,8 \mathrm{SDi}$ & Sangat Tinggi/ \\
\hline & & Sangat Siap \\
\hline 2. & $\begin{array}{l}\text { di atas }(\mathrm{Mi}+0,6 \mathrm{SDi} \\
) \text { s.d. }(\mathrm{Mi}+1,8 \mathrm{SDi})\end{array}$ & Tinggi / Siap \\
\hline 3. & di atas $(\mathrm{Mi}-0,6 \mathrm{SDi}$ & Sedang/ Cukup \\
\hline 4. & $\begin{array}{l}\text { di atas ( } \mathrm{Mi}-1,8 \mathrm{SDi} \\
\text { ) s.d. ( } \mathrm{Mi}-0,6 \mathrm{SDi})\end{array}$ & $\begin{array}{l}\text { Rendah/ Tidak } \\
\text { siap }\end{array}$ \\
\hline & ( $\mathrm{Mi}-3 \mathrm{SDi})$ s.d. ( & Sangat Rendah/ \\
\hline 5. & $\mathrm{Mi}$ & $\begin{array}{l}\text { Sangat } \\
\text { Siap }\end{array}$ \\
\hline
\end{tabular}

Tabel.3 Pengkategorisasi Kesiapan Guru

\begin{tabular}{|c|c|c|c|c|}
\hline No. & Interval & $\begin{array}{l}\text { Jum } \\
\text { lah }\end{array}$ & $\%$ & Kategori \\
\hline 1. & $\begin{array}{l}\text { di atas } \\
75,6 \text { s.d. } \\
90\end{array}$ & 63 & $\begin{array}{l}30 \\
00 \\
\%\end{array}$ & $\begin{array}{l}\text { Sangat Tinggi } \\
\text { / Sangat Siap }\end{array}$ \\
\hline 2. & $\begin{array}{l}\text { di atas } \\
61,2 \text { s.d. } \\
75,6\end{array}$ & 121 & $\begin{array}{l}57 \\
62 \\
\%\end{array}$ & Tinggi / Siap \\
\hline 3. & $\begin{array}{l}\text { di atas } \\
46,8 \text { s.d. } \\
61,2\end{array}$ & 16 & $\begin{array}{l}7,6 \\
2 \%\end{array}$ & $\begin{array}{l}\text { Sedang/ } \\
\text { Cukup Siap }\end{array}$ \\
\hline 4. & $\begin{array}{l}\text { di atas } \\
32,4 \text { s.d. } \\
46,8\end{array}$ & 6 & $\begin{array}{l}2,8 \\
6 \%\end{array}$ & $\begin{array}{l}\text { Rendah/ Tidak } \\
\text { siap }\end{array}$ \\
\hline 5. & $\begin{array}{l}18 \text { s.d. } \\
32,4\end{array}$ & 4 & $\begin{array}{l}1,9 \\
0 \%\end{array}$ & $\begin{array}{l}\text { Sangat Rendah } \\
\text { / Sangat Tidak } \\
\text { Siap }\end{array}$ \\
\hline & umlah & 210 & $\begin{array}{l}100 \\
\%\end{array}$ & \\
\hline
\end{tabular}

Bila dilihat pada tabel di atas, terdapat hasil pengisian angket kesiapan guru RA di Bangkalan pada pembelajaran daring yang telah diisi oleh responden. 121 angket yang didapatkan menunjukkan guru dalam kategori tinggi atau siap dengan presentase sebesar $57,62 \%$. Berdasarkan hasil penelitian yang ada, cukup kontradikti dengan penelitian dan asumsi lain yang menunjukkan bahwa kemampuan guru dalam menggunakan teknologi informasi komputer masih rendah (Febrialismanto \& Nur, 2020) sehingga akan berpengaruh juga pada kesiapan guru dalam pembelajaran daring.

Berbeda dengan penelitian sebelum-nya yang memperlihatkan kemampuan TIK guru masih rendah. Kesiapan guru dalam pembelajaran daring sudah mulai meningkat saat ini. Hal ini diperkuat dengan penelitian yang melihat bahwa sebagian besar guru telah siap dalam melaukan pembelajaran daring (Jalal, 2020) Perubahan kondisi ini bisa terjadi karena beberapa hal yang terjadi selama pembelajaran daring berlangsung diantaranya keikutsertaan para guru dalam webinar pengembangan pembelajaran daring yang memungkinkan bertambahnya wawasan dan memunculnya ide baru pada rancangan pembelajaran.

Namun selaras dengan hasil penelitian yang di lakukan oleh Astutiningtyas dengan hasil penelitian teknologi digital memiliki peran penting dalam peningkatan kreativitas Selama Covid-19 (Astutiningtyas \& Yanuartuti, 2020). Sejalan dengan perkembangan dunia yang semakin pesat, khususnya pembelajaran membuat karya seni dengan media digital yang matang, maka Akan meningkatkan kreativitas pembelajaran.

Banyaknya aplikasi pada gawai yang biasa digunakan oleh para guru untuk berkomunikasi saat ini digunakan pula untuk melakukan pembelajaran. Aplikasi whatsapp merupakan salah satu aplikasi yang paling mudah digunakan karena biasa digunakan sebelumnya dan memiliki fitur yang mendukung untuk melakukan pembelajaran (Riadil et al., 2020). Selain tersedianya aplikasi yang mudah digunakan oleh guru banyaknya pelatihan yang dilakukan secara daring pun dapat mempenga-ruhi kompetensi pedagogik guru dan berefek positif pada keseharian guru (Ciptaningtyas et al., 2020). Berdasarkan penelitian tersebut menjelaskan adanya beberapa faktor yang mendukung guru untuk berkembang dalam pelaksanaan pembelajaran daring, sehingga kesiapan guru dalam pembelajaran daring saat ini mulai tinggi. Ke depannya pembelajaran di dunia pendidikan anak usia dini dapat dilakukan secara blended learning, agar pelaksanaan pendidikan anak usia dini pun dapat optimal dan guru dapa mengembangkan sumber dan media belajar dari teknologi yang ada. 


\section{SIMPULAN}

Pembelajaran daring yang harus dilakukan oleh para guru saat pandemi tetap harus menghasilkan pembelajaran yang baik. Pembelajaran daring dapat dilakukan secara optimal dengan kesiapan yang baik dari segala pihak yang berkaitan. Kesiapan guru dalam pembelajaran merupakan salah satu cara agar hasil dalam pembelajaran daring berjalan dengan baik. Sayangnya skala yang dikhususkan untuk mengukur kesiapan guru PAUD di Indonesia dalam pembelajaran daring belum ada, sehingga memerlukan adaptasi skala yang tepat untuk mengukur kesiapan guru RA di Bangkalan pada pembelajaran daring. Skala yang ada lebih berfokus pada pendidikan yang lebih tinggi seperti Sekolah Menengah Atas hingga Universitas, namun ada satu skala yang cukup tepat untuk mengukur kesiapan guru PAUD dalam pembelajaran daring, yaitu TORLM.

Berdasarkan hasil adaptasi dan pengujian secara statisti skala TROLM (Teacher Readiness for Online Learning Maeasure) merupakan skala yang sesuai dan dapat digunakan untuk mengukur kesiapan guru RA di Bangkalan pada pelaksanaan pembelajaran daring. Sehingga kuesioner yang disebarkan kepada narasumber adalah hasil pengembangan dari skala TROLM. Hasil perhitungan skala TROLM menunjukkan bahwa guru RA di Bangkalan berapa pada kesiapan yang cukup tinggi dalam pembelajaran daring. Hal ini bisa terjadi karena banyaknya pelatihan yang dilakukan secara daring selama pandemi terjadi sehingga guru semakin terbiasa menggunakan teknologi digital serta internet dalam pembelajaran. Selain itu adanya aplikasi komunikasi yang memiliki fitur lengkap untuk melakukan pembelajaran daring memudahkan guru dalam melakukan pembelajaran daring.

Berdasarkan hasil penelitian yang demikian maka besar kemungkinan pembelajaran di dunia pendidikan anak usia dini dapat dilakukan secara blended learning, agar pelaksanaan pendidikan anak usia dini pun dapat optimal dan guru dapat mengembangkan sumber dan media belajar dari teknologi yang terus berkembang. Hal yang belum terteliti adalah antusiasme anak usia dini dalam mengikuti pembelajaran daring. Serta tindak lanjud pada tingkat perkembangan anak selama proses pembelajaran daring berlangsung. Arah yang lebih luas lagi yaitu pada pembangkan berbagai platform, media digital yang ramah untuk anak usia dini sehingga dapat menunjang kegiatan blended learning dalam dunia pendidikan anak usia dini.

\section{DAFTAR PUSTAKA}

Andrianto Pangondian, R., Insap Santosa, P., \& Nugroho, E. (2019). Faktor - Faktor Yang Mempengaruhi Kesuksesan Pembelajaran Daring Dalam Revolusi Industri 4.0. Sainteks 2019, 56-60.

Astutiningtyas, R., \& Yanuartuti, S. (2020). Relokasi Pembelajaran Seni Dalam Bentuk Daring Online Untuk Meningkatkan Kreativitas Selama Pandemi Covid-19. Pendidikan Seni Budaya, 4(13), 138-145.

Ayuni, D., Marini, T., Fauziddin, M., \& Pahrul, Y. (2020). Kesiapan Guru TK Menghadapi Pembelajaran Daring Masa Pandemi Covid19. Jurnal Obsesi : Jurnal Pendidikan Anak Usia Dini, $5(1), \quad 414$. https://doi.org/10.31004/obsesi.v5i1.579

Cahyati, N. (2020). Kegiatan Home Literacy Dalam Mengembangkan Kemampuan Awal Membaca Anak Usia Dini Di Masa WFH. Jurnal Golden Age, 4(01), 160-166. https://doi.org/10.29408/jga.v4i01.2219

Cahyati, N., \& Kusumah, R. (2020). Peran Orang Tua Dalam Menerapkan Pembelajaran Di Rumah Saat Pandemi Covid 19. Jurnal Golden Age, Universitas Hamzanwadi, 04(1), 4-6.

Churiyah, M., Sholikhan, S., Filianti, F., \& Sakdiyyah, D. A. (2020). Indonesia Education Readiness Conducting Distance Learning in Covid-19 Pandemic Situation. International Journal of Multicultural and Multireligious Understanding, 7(6), 491. https://doi.org/10.18415/ijmmu.v7i6.1833

Ciptaningtyas, A., Yetti, E., \& Hartati, S. (2020). Metode Pelatihan dan Persistensi Berpengaruh terhadap Kompetensi Pedagogik Guru PAUD. Jurnal Obsesi : Jurnal Pendidikan Anak Usia Dini, 4(2), 686.

https://doi.org/10.31004/obsesi.v4i2.440

Dong, C., Cao, S., \& Li, H. (2020). Young children's online learning during COVID-19 pandemic: Chinese parents' beliefs and attitudes. Children and Youth Services Review, $\quad 118$ (September), 105440. https://doi.org/10.1016/j.childyouth.2020.10 5440

Febrialismanto, \& Nur, H. (2020). Kemampuan Guru Menggunakan TIK Untuk Pengembangan di Taman Kanak-Kanak. KINDERGARTEN: Journal of Islamic Early 
Childhood Education, 2(2), 101-111. https://doi.org/10.24014/kjiece.v2i2.8296

Ha, O., JM, N., \& An, W. (2014). E-Learning Readiness Assessment Model in Kenyas' Higher Education Institutions: A Case Study Of University of Nairobi. International Journal of Scientific Knowledge, 5(6), 2941.

Harahap, S. A., Dimyati, \& Purwanta, E. (2021). Problematika Pembelajaran Daring dan Luring Anak Usia Dini bagi Guru dan Orang tua di Masa Pandemi. Jurnal Obsesi: Jurnal Pendidikan Anak Usia Dini, 5(2), 18251836.

https://doi.org/10.31004/obsesi.v5i2.1013

Hung, M. L. (2016). Teacher readiness for online learning: Scale development and teacher perceptions. Computers and Education, 94, 120-133.

https://doi.org/10.1016/j.compedu.2015.11.0 12

Jalal, M. (2020). Kesiapan Guru Menghadapi Pembelajaran Jarak Jauh Di Masa Covid-19. SMART KIDS: Jurnal Pendidikan Islam Anak Usia Dini, 2(1), 35-40. https://doi.org/10.30631/smartkids.v2i1.61

Jayawardana, H. B. ., Zahro, I., \& Pertiwi, E. P. (2020). Identifikasi Kesulitan Guru Paud Di Masa Pandemi Covid-19 Dan Solusinya. PAUDIA : Jurnal Penelitian Dalam Bidang Pendidikan Anak Usia Dini, 9(2), 40-50. https://doi.org/10.26877/paudia.v9i2.6647

Ke, H., AlSaqqaf, A., \& Swanto, S. (2020). Elearning readiness among English language teachers in Sabah, Malaysia: A pilot study. 2(September), 120-127.

Riadil, I. G., Nuraeni, M., \& Prakoso, Y. M. (2020). Persepsi Guru Paud Terhadap Sistem Pembelajaran Daring Melalui Whatsapp Di Masa Pandemi Covid-19. PAUDIA : Jurnal Penelitian Dalam Bidang Pendidikan Anak Usia Dini, 9(2), 89-110. https://doi.org/10.26877/paudia.v9i2.6574

Saputro, S. D. (2018). Studi Perbandingan Pendidikan Umum Dan Agama Di Kabupaten Bangkalan. Pamator Journal, 11(1), 32-41.

Sutarna, N., Acesta, A., Cahyati, N., Giwangsa, S. F., \& Iskandar, D. (2022). Dampak Pembelajaran Daring terhadap Siswa usia 5-8 tahun. 6(1), 288-297. https://doi.org/10.31004/obsesi.v5i2.1265

Wulandari, H., \& Purwanta, E. (2020). Pencapaian Perkembangan Anak Usia Dini di Taman Kanak-kanak selama Pembelajaran Daring di
Masa Pandemi Covid-19. Jurnal Obsesi: Jurnal Pendidikan Anak Usia Dini, 5(1), 452.

https://doi.org/10.31004/obsesi.v5i1.626 